\title{
Developing Decision Making Grid for Maintenance Policy Making Based on Estimated Range of Overall Equipment Effectiveness
}

\author{
Arash Shahin (Corresponding author) \\ Department of Management, University of Isfahan, Isfahan, Iran \\ 1.242 Saeb Avenue 81848-13713, Isfahan, Iran \\ Tel: 98-311-793-2040 E-mail: arashshahin@hotmail.com \\ Mohammad Reza Attarpour \\ Department of Management, University of Isfahan, Isfahan, Iran \\ E-mail: attarpour.mailbox@yahoo.com
}

Received: August 4, 2011

doi:10.5539/mas.v5n6p86

\author{
Accepted: October 23, $2011 \quad$ Published: December 1, 2011 \\ URL: http://dx.doi.org/10.5539/mas.v5n6p86
}

\begin{abstract}
In today world of competition, one of critical success factors influencing survival, profitability, and competitive advantage of manufacturing organizations is to select appropriate maintenance policy. While decision making grid (DMG) provides a relatively comprehensive perspective to managers for policy making, its criteria does not include overall equipment effectiveness (OEE), perhaps since OEE is mostly used in one of the policies, i.e. total productive maintenance (TPM). In this article, the traditional DMG has been modified, in which the range of OEE has been estimated and replaced by one of the grid's criteria. A case study has been conducted in one of the steel manufacturing companies of Iran and data has been obtained and analyzed from 30 machines of the company. The major finding of this investigation is that although OEE is an indicator of TPM, its different values might suggest different policies in addition to TPM.
\end{abstract}

Keywords: Overall equipment effectiveness, Maintenance, Decision making grid

\section{Introduction}

Selection of proper maintenance strategies result in energy efficiency. When costs need to be cut and availability increased attention is ultimately drawn to the maintenance strategies, regardless of the industry type. All sub-station equipments must therefore receive high standard of maintenance so that they perform reliably throughout their life span. Maintenance and reinvestments are important parts of the asset management, as they are measures to control the risks faced by the companies such as power plants, energy distributor companies and computerized systems. Electric power utilities have always employed maintenance programs to keep their equipment in good working condition for as long as it is feasible.

Measuring maintenance performance and analyzing and controlling it has a long way since WW II. Nowadays many companies look at grid management as a strategic issue that impacts on all aspects of organizational performance including competition, efficiency, quality and security. This strategic vision that is based on organizational business strategy results in grid coordination and integration and other organizational decision making such as production management, quality management, business expansion (Gebauer et al., 2008; Aoudia et al., 2008) and lack of understanding and little attention to the relationship and coordination between grid activities and business strategy and having a traditional attitude towards grid activities as " necessary loss" that should be decreased, can have bad effects on organizational competition capability and its presence in international competition scene and global markets (Pinjala et al., 2006). The challenge of designing an ideal model for grid activities has been the subject of many surveys and a basic issue in improving effectiveness and efficiency in grid management, and ultimately fulfilling organizational objectives (Mishra et al., 2006).

Several researchers such as Cholasuke et al. (2004) and Parida and Kumar (2006) have emphasized the strategic role of effective and efficient grid management in competitive advantage, continuous improvement, supporting productive activities, performance improvement, and protecting heavy industries and high investment in 
machinery and equipment maintenance in an appropriate performance condition. Grid planning has many impacts on the product quality, process efficiency, production cost, effective performance and continuous improvement. In other words, since each maintenance strategy is suiTable for a special condition of machinery in terms of frequency of failure and breakdown time, selecting proper strategy leads to increasing quality, efficiency, performance and continuous improvement and reduction of cost. It also plays a critical role in protecting activities related to production (Jin et al., 2007). Nowadays the grid plays a key role in long term profitability of organization (Parida \& Kumar, 2006). Thus in the current competitive world, there has been emphases on developing and using appropriate grid policies as tools and techniques for ensuring appropriate maintenance activities.

In today's dynamic and modern environment, vital decisions regarding grid operation rely on available information and how to use it in an appropriate setting (Emmanouilidis et al., 2009). In reaction to competitive and economic pressures and to enable optimization, mathematical tools and operational research (OR) techniques have been used in grid planning, which results in better grid models (Mathew, 2007). Decision Making Grid (DMG) is one of such tools which uses the Analytic Hierarchy Process and relies on fuzzy logic, and uses the information obtained from Computerized Maintenance Management system (CMMS) to propose an appropriate grid policy and these can assist managers in areas such as; analysis, decision making, and choosing appropriate grid policies. DMG acts as a plan in which, by considering two criteria, of the time of failures and their frequencies, the status of various machinery is determined and the appropriate grid policy is proposed (Labib, 2004). Tahir et al. (2008) has used DMG in small and medium size industries as a system of protecting grid decisions and optimizing these activities. However, as Aoudia et al. (2008) emphasizes, it is essential to show losses created due to ineffective grid management and outcomes to senior managers in order to convince them to consider the importance of DMG.

Much attention has recently been given to performance measurement (Parida and Kumar, 2006). Measuring performance provides necessary information to managers for decision making (Parida, 2007). Research has demonstrated that those organizations which have used performance measurement have better performance than those who do not use performance management systems (Kennerly and Neely, 2003; Parida, 2007). Garg and Deshmukh (2006) have reviewed the grid management history and found that Overall Equipment Effectiveness (OEE) indicator can play a major role in DMG. OEE is a quantitative indicator for measuring equipments' effectiveness which was proposed by Nakajima (1988) in Japan, and increasingly have been used in recent years. OEE is the ratio of process effectiveness (of the desired product with the determined speed ratio) when it is planned for production. OEE allows for the detection of hidden capacities of equipments and their hidden costs, and can increase equipments effectiveness. Overall equipment effectiveness is the result of availability, speed ratio and quality ratio (Hansen, 2001).

Zuashkiani et al. (2011) attempted to map dynamically OEE to upgrade financial management activities. They tried to find why in spite of clear emphases on maximizing OEE in organizations, there are many changes and differences between organizations in the ratio of this indicator. To address this issue, they used mapping of guiding circles of maintenance and their contrasting relationships in the organization, and stated that the performed activities with short term objectives (as an incorrect term) have ruined organizational capabilities in long term and will result in decreasing OEE. Anvari et al. (2010) introduced a new method entitled OEE-BM for measuring equipment effectiveness in the steel industry. This new method reflects internal and external changes in markets, and therefore is an appropriate tool for improvement management and administration. Reyes et al. (2010) surveyed the relationship between two indicators of Process Capability (PC) and OEE and found that any improvement in the process capability has a positive impact on OEE.

These studies as well as other research about OEE show that this indicator is still considered as one of the most important commonly used criterion in measuring equipment performance. In this respect, in spite of close relationship between this indicator and the grid system, it seems integration of OEE and DMG has not been empirically tested and addressed in the literature .

In OEE, the ratio of availability can determine the grid performance (Jin et al., 2007). It can impact on other two ratios, i.e. speed and quality ratios. Therefore the authors believe that availability can make the bridge between OEE indicator and DMG in determining appropriate grid policies. The aim of this investigation is to estimate the relationship between OEE and DMG, whereby provides an appropriate sight to managers in order to select effective and efficient maintenance strategy. In the following, the grid management, DMG and OEE are introduced. New methodology is then developed, followed by case study, discussion and conclusions. 


\section{Grid management and Decision Making Grid (DMG)}

\subsection{Grid management}

Many companies realize grid management as an essential and inseparable part of production activities. They argue that an effective and efficient grid management implies that by grid planning, competitive advantage can be achieved. One of the major costs in manufacturing companies is grid cost that can include 15 to 70 percent of production costs which vary in different industries (Bashiri et al., 2011). In another estimation, it is found that 20 to 30 percent of operational costs of companies include grid costs; thus appropriate planning for grid activities improves profitability (Sachdeva et al., 2008). Shahin and Ahmadi (2008) state that an excellent grid plan can have advantages like achieving 90 to 98 percent availability, reducing failure rate to 50 to 90 percent, increasing capacity to 10 to 30 percent, improving quality and reducing failure. Grid can be defined as activities that aim to rapidly save or recover security, performance, insurability, availability of structures, systems and components of organization to ensure best performance, when necessary (Weinstein and Chung, 1999). Grid activities are implemented for repairing failure equipments, maintaining equipment conditions, and preventing damage, and ultimately can result in reducing production waste, time of failure, and dangers related to security and environment (Nguyen and Bagajewicz, 2008).

Grid objective value has been composed of two parts of total grid costs (preventing grid, corrective grid, labor cost, inventory costs, quality, obsolescence, and down equipments costs) plus economic costs (economic costs related to reducing work speed equipments, and unavailability to equipments during repair time) that should be minimized (Durango-Cohen and Sarotipand, 2009; Wen et al., 2009).

Considering the above explanation, it can be concluded that using appropriate grid policies and activities can considerably influence quality, overall performance, effectiveness, and efficiency of organizational operations, whereby the organization can obtain competitive advantages such as efficiency, long term profitability and value benefits (Alsyouf, 2009).

Various resources exist on determining the philosophy, methods, and strategies of a grid. Gebauer et al. (2008) classified grids into three categories :

i) Corrective grid: Grid activities can focus on repairing failure equipments or trimming maintenance costs. Relying on this category solely considers performance issues and is ineffective and costly .

ii) Predictive grid: A series of performed duties in a specific time, production ratio, and equipment conditions that result in increasing life time or in discovering critical failures (Garg and Deshmukh, 2006). The key point in predictive maintenance (PM) is to control closely equipments' performance conditions. Companies in this category can use condition based grid or insurability based grid that provides grid needs and programs, respectively. PM includes condition Based Maintenance (CBM) and Reliability Centered Maintenance (RCM). $\mathrm{CBM}$ is a program that proposes grid activities based on condition monitoring information. In general, there are two types of duties in CBM which include diagnosis with the aim of discovering disable components and mode of failure, and prognoses i.e. predicting durability of remained components or estimating the probability of the point that components still work before failure happens (Jardine et al., 2006). The CBM components are generally composed of four phases of data collection, data analyses, decision making, and implementation (Veldman et al., 2011). RCM is a systematic method that is used for optimizing predictive and preventing grid programs to improve equipments efficiency (time, performance and quality) and aims to minimize costs, simultaneously. RCM methodology concentrates more on system duties maintenance than returning equipments to ideal conditions. RCM concentration is on determining the point that which preventing grid policy is needed to maximize the reliability of equipments and systems (Sachdeva et al., 2008).

iii) Comprehensive efficient grid: Total Productive Maintenance (TPM) impacts on production process by affecting on equipment availability, production rate, and quality output. The objectives of TPM include maximizing equipments effectiveness, developing an efficient grid system for all equipments lifetime, involving all executive parts, planning, equipments designing and maintenance and promoting continuous improvement by involving all employees and by motivation management. Garg and Deshmukh, (2006) state that TPM uses quality circles and has advantages such as better understanding of equipment performance, improving team work, and less incompatibility between grid and production methods.

\subsection{Decision Making Grid (DMG)}

Regarding the increasingly development of computers, Computerized Maintenance Management System (CMMS) have many applications. This system is a software program that is applied to control activities and resources and also administrate and report actions (Fernandez, et al., 2003). CMMS is applied to reduce failure 
time and their frequency by increasing effectiveness and efficiency of activities related to maintenance and to achieve this objective, data collection is required. Although CMMS as one of the important and central components of maintenance department has been used in many organizations, these systems solely provide facilities for data collection and cannot assist managers to analyze and make decision. Labib (2004) calls this lack as "Black Hole", and in order to remove this shortage he proposes DMG. DMG acts as a plan that determines the worst condition of equipments based on two criteria of the time and frequency of failures and proposes proper maintenance and repair policies as a basic solution. The objective of DMG is to determine proper policies that cause equipments movement towards improved condition (Labib, 2004). DMG can also be used as a practical way to obtain continuous improvement. To determine equipments statue in DMG, information obtained by CMMS database is needed. DMG is illustrated in Figure 3.

Fernandez et al. (2003) suggested the following limit values for the two criteria of downtime and frequency of failures on each of the two axes:

$$
\begin{gathered}
\text { High value }=\text { Highest value } \\
\text { Highest value }=\text { Medium to high value } \\
\text { Highest value }=\text { Medium to low value } \\
\text { Low value }=\text { Lowest value }
\end{gathered}
$$

Labib (2004) suggested that in DMG, downtime can be replaced by Mean Time to Repair (MTTR), and failure frequency can be replaced by Mean time between Failures (MTBF). Considering the point that MTBF and failure frequency have reverse interrelationship, in the DMG of this study (Figure 2), the reverse of MTBF means failure frequency.

It is important to note that in the DMG, all the three groups of addressed grids are included, i.e. OTF refers to corrective grid and CBM and TPM are directly located in the grid. In addition, since MTTR and MTBF are the two major indicators of RCM (Han, 2009), it seems that this maintenance policy is also included in the grid.

\section{Overall Equipment Effectiveness (OEE)}

Considering increasing global competition, one of the ways of increasing effectiveness is performance measurement. Production improvement and successful control can only take place when a proper performance measurement system is used (Bamber et al., 2003). Therefore there is no doubt about the importance of performance measurement (De Ron and Rooda, 2005), and undoubtedly OEE can be used as a tool for measurement, control, and performance improvement (Bamber et al., 2003).

One of the major indicators for determining world class companies is the effectiveness of plants, and OEE is a good representative for this indicator. Using OEE indicator and arranging an ordered report about performance of machineries and equipments will help any industry to concentrate on parameters, which are important for its success (Hansen, 2001).

The application of OEE is not limited to the manufacturing industry and it has been developed for service applications (Shahin, 2005). One of the key factors in OEE is data collection. OEE includes indexes of downtime and other losses related to production that reduces operational ability. The reason of measuring such losses is to find their causes and using information to eliminate them (Ljungberg, 1998).

Losses are activities that in spite of using resources do not make values, and the aim of OEE is o to recognize them. According to Nakajima (1988) there are six major losses that can be divided into three general categories of losses related to disability, losses reducing speed, and losses reducing quality. The OEE indicator is demonstrated in Figure 3.

Wang and Pan (2011) considered quality improvement of OEE and UPH data by using ADC system in semiconductor assembly industry and classified and analyzed OEE losses by using fish bone chart. The point worth mentioning is that each organization should have specific framework for classifying losses by considering its conditions (Bamber et al., 2003). In order to determine OEE ratio in world class companies, many discussions have been made by scientists. Nakajima (1988) suggests that the ideal values for the OEE components include more than 90 percent availability, more than 95 percent performance, and more than 99 percent quality. As a result, the OEE would be 85 percent.

Kotze (1993) stated that the value of OEE higher than 50 percent is more realistic and accepTable. Ericsson (1997) explained that accepTable OEE can vary from 30 to 80 percent. Ljungberg (1998) suggested the medium value of OEE as about 55 percent (availability 80 percent, performance 68 percent, and quality 99 percent). The 
important point is that regarding different criteria that exist in each industry, this issue that one can state an optimized number for OEE seems to be difficult (Dal et al., 2000).

\section{Research methodology}

In order to make relationship between OEE indicator and DMG, two indicators of MTBF and MTTR have been used. Dependent variable of this study is the OEE indicator and there are two independent variables of MTTR and MTBF. Dependent variable is composed of three other dependent variables i.e. availability ratio, performance ratio, and quality ratio. Calculation related to the OEE indicator that has been used in this investigation is addressed as follows:

$$
\begin{gathered}
\text { Availability }=\frac{\text { MTBF }}{\text { MTBF }+ \text { MTTR }} \\
\text { Performance }=\frac{\text { Real capacity }}{\text { Nominal capacity }} \\
\text { Quality }=\frac{\text { Total products }- \text { Defective products }}{\text { Total products }}
\end{gathered}
$$

Considering OEE indicator as dependent variable and MTBF criterion as independent variable, their linear regression is estimate by SPSS software, and the range of OEE indicator is specified in order to be located in the DMG and will be replaced with MTBF, thus a more comprehensive indicator than MTBF and frequency of failure will be applied in DMG that in addition to improving grid, shows the effective role of OEE indicator for determining appropriate grid policy and assisting managers in decision making. Therefore, considering the linear relationship between OEE indicator and MTBF criterion, DMG is developed as demonstrated in Figure 4.

As it is clear, Figure 4 and Figure 2 are the same and in Figure 4, OEE is replaced by MTBF. The research approach is illustrated and summarized in Figure 5. After data collection and computing MTTR and MTBF, availability ratio is calculated; then the data related to performance ratio and quality ratio are obtained, and these two ratios are computed. Considering the three computed ratios, the OEE indicator is determined for the equipments. By determining high, medium and low values of the scales of vertical and horizontal axes associated with MTBF and MTTR, the DMG matrix is developed. In the next stage, the linear regression between the two indicators of OEE and MTBF is estimated and the value of corresponding OEE as a function of MTBF is computed.

The OEE value is replaced by the ratio of MTBF in DMG. Ultimately, considering the two new indicators of MTTR and OEE, the equipments are positioned in the developed DMG and appropriate maintenance policy is proposed for the equipments.

\section{Case study and findings}

The data is gathered from 30 equipments of various production lines of a steel manufacturing plant in Isfahan. The equipments are selected with respect to the strategic role they play in gaining competitive advantages in the plant. In Table 1, the data obtained from the equipments is presented. Based on the data of Table 1, a DMG is formed in which, MTBF and MTTR values are deployed on vertical and horizontal axes, respectively. The 30 equipments are then positioned in the cells as illustrated in Figure 6. As it is clear, half of the equipments are positioned in the OTF cell.

In Table 2, the obtained results of linear regression test between OEE indicator and MTBF criterion analyzed by SPSS software is addressed. As it is shown, the linear regression significant value is meaningful $(<0.05)$ and the linear relationship between the two variables is approved.

The estimated equation is derived as:

$$
\mathrm{OEE}=18185+0.286 \mathrm{MTBF}
$$

Based on the estimation of OEE, its range is computed considering the corresponding values of MTBF and the new DMG is developed using the values of OEE and MTTR (Figure 7). 


\section{Discussion and conclusions}

Gaining durable competitive advantage, increasing competition, globalization, and increasing role of grid in long term profitability of organization lead managers to concentrate more on grid activities. All grid policies individually or in combination increase reliability and availability of systems and equipments, which in turn result in cost reduction (Da Silva et al., 2008). Two of the criteria which play significant role in availability are Mean Time Between Failures (MTBF) and Mean Time To Repair (MTTR). Labib (1998) proposed an approach entitled DMG for selecting appropriate grid policy that uses the criteria of determining availability (MTTR, MTBF). In this respect, measuring performance is also considered as a key factor of organizational success that organizations consider them as more effective. One of the key indicators of performance measurement is OEE that is addressed as a quantitative indicator for measuring equipments' effectiveness and grid performance. Grid managers and experts' views in today's competitive world regarding machineries conditions and records should be in a different and exclusive way; in other words, an appropriate grid policy for an equipment or production line might be inappropriate policy for another one. Thus for any equipment, an exclusive policy should be used.

In this article, the OEE indicator was estimated based on MTBF and a new DMG was developed, respectively. Traditionally, according to the equation of OEE, a direct relationship exists between OEE and Availability and as much as availability increases/decreases, the OEE indicator will either increase/ decrease. However, since OEE is an indicator of Total Productive Maintenance (TPM), initially it seems that any value represented by OEE is in framework of TPM, while the results of this investigation suggest a different conclusion. Considering the results, it is found that at least one of the criteria of MTBF or MTTR should be in the middle range in order to select the policy of TPM. Therefore, in this study, an attempt was made to estimate a linear relationship between OEE and MTBF in order to develop DMG for making more accurate maintenance policies.

Regarding the obtained results from the case study in the steel manufacturing company, the range of OEE and MTTR indicators were defined as:

- Low OEE: almost between 21.5 to 35.5 percent

- Medium OEE: almost between 31.5 to 53 percent

- High OEE: almost between 53 to 70 percent

- Low MTTR: between 3 to 25

- Medium MTTR: between 25 to 50

- High MTTR: between 50 to 75

Respectively, when OEE is between 31.5 to 53 percent, using TPM is permanent, but in other cases only when MTTR is between 25 to 50 , using TPM is justifiable.

It is important to note that in this study, there was a strong (0.858) and significant linear correlation between OEE and MTBF and this relationship might not be always the same in other cases and industries, and this can be a potential subject for future studies.

\section{References}

Alsyouf, E. (2009). Maintenance practices in Swedish industries: Survey result. International Journal of Production Economics, 121(1), 212-223. http://dx.doi.org/10.1016/j.ijpe.2009.05.005

Anvari, F., Edwards, R. \& Starr, A. (2010). Evaluation of overall equipment effectiveness based on market. Journal of Quality in Maintenance Engineering, 16(3), 256-270. http://dx.doi.org/10.1108/13552511011072907

Aoudia, M., Belmokhtar, O., \& Zwingelstein, G. (2008). Economic impact of maintenance management ineffectiveness of an oil and gas company. Journal of Quality in Maintenance Engineering, 14(3), 237-261. http://dx.doi.org/10.1108/13552510810899454

Bamber, C. J., Castka, P., Sharp, J. M., \& Motara, Y. (2003). Cross functional team working for overall equipment effectiveness (OEE). Journal of Quality in Maintenance Engineering, 9(3), 223-238. http://dx.doi.org/10.1108/13552510310493684

Bashiri, M., Badri, H., \& Hejazi, T. H. (2011). Selecting optimum maintenance strategy by fuzzy interactive linear assignment method. Applied Mathematical Modelling, 35(1), 152-164. http://dx.doi.org/10.1016/j.apm.2010.05.014 
Cholasuke, C., Bhardwa, R., \& Antony, A. (2004). The status of maintenance management in UK manufacturing organisations: Results from a pilot survey. Journal of Quality in Maintenance Engineering, 10(1), 5-15. http://dx.doi.org/10.1108/13552510410526820

Da, Silva, C. M. I., Cabrita, C. M. P., \& Matias, J. C. O. (2008). Proactive reliability maintenance: A case study concerning maintenance service costs. Journal of Quality in Maintenance Engineering, 14(4), 343-355. http://dx.doi.org/10.1108/13552510810909957

Dal, B., Tugwell, P., \& Greatbanks, R. (2000). Overall equipment effectiveness as a measure of operational improvement: A practical analysis. International Journal of Operations \& Production Management, 20(12), 1488-1502. http://dx.doi.org/10.1108/01443570010355750

De, Ron, A. J., \& Rooda, J. E. (2005). Equipment Effectiveness: OEE Revisited. IEEE Transaction on Semiconductor Manufacturing, 18(1), 190-196. http://dx.doi.org/10.1109/TSM.2004.836657

Durango-Cohen, P. L., \& Sarutipand, L. (2009). Maintenance optimization for transportation systems with demand responsiveness. Transportation Research, Part C17, 337-348. http://dx.doi.org/10.1016/j.trc.2009.01.001

Emmanouilidis, C., Liyanage, J. P., \& Jantunen, E. (2009). Mobile solutions for engineering asset and maintenance management. Journal of Quality in Maintenance Engineering, 15(1), 92-105. http://dx.doi.org/10.1108/13552510910943903

Ericsson, J. (1997). Disruption Analysis - An Important Tool in Lean Production. Department of Production and Materials Engineering, Lund: Lund University.

Fernandez, O., Labib, A. W., Walmisley, R., \& Petty, D. J. (2003). A decision support maintenance management system: Development and implementation. International Journal of Quality \& Reliability Management, 20(8), 965-979. http://dx.doi.org/10.1108/02656710310493652

Garg, A., \& Deshmukh, S. G. (2006). Maintenance management: literature review and directions. Journal of Quality in Maintenance Engineering, 12(3), 205-238. http://dx.doi.org/10.1108/13552510610685075

Gebauer, H., Putz, F., Fischer, T., Wang, C., \& Lin, J. (2008). Exploring maintenance strategies in Chinese product manufacturing companies. Management Research News, 31(12), 941-950. http://dx.doi.org/10.1108/01409170810920648

Han, L. (2009). The self-adaptation to dynamic failures for efficient virtual organization formations in grid computing context. Chaos, Solitons \& Fractals, 41(3), 1085-1094. http://dx.doi.org/10.1016/j.chaos.2008.04.043

Hansen, R. C. (2001). Overall Equipment Effectiveness: A powerful production/maintenance tool for profits. New York, NY: Industrial Press Inc.

Jardine, A., Lin, D., \& Banjevic, D. (2006). A review on machinery diagnostics and prognostics implementing condition based maintenance. Mechanical Systems \& Signal Processing, 20(7), 1483-1510. http://dx.doi.org/10.1016/j.ymssp.2005.09.012

Jin, J., Chaipradubkiat, P., Shi, J., \& Chan, L. Y. (2007). Optimal Selection of Maintenance Strategies Considering Variation of Operation Availability. Proceedings of the 2007 Industrial Engineering Research Conference, May 19-23, Nashville, TN.

Kennerly, M., \& Neely, A. (2003). Measuring performance in a changing business environment. International Journal of Operations \& Production Management, 23(2), 213-229. http://dx.doi.org/10.1108/01443570310458465

Kotze, D. (1993). Consistency, accuracy lead to maximum OEE benefits. TPM Newsletter, 4(2), AITPM, Productivity, Inc., Norwalk, November.

Labib, A. W. (1998). World class maintenance using a computerised maintenance management system. Journal of Quality in Maintenance Engineering, 4(1), 66-75. http://dx.doi.org/10.1108/13552519810207470

Labib, A. W. (2004). A decision analysis model for maintenance policy selection using a CMMS. Journal of Quality in Maintenance Engineering, 10(3), 191-202. http://dx.doi.org/10.1108/13552510410553244

Ljungberg, O. (1998). Measurement of overall equipment effectiveness as a basis for TPM activities. International Journal of Operations \& Production Management, 18(5), 495-507. http://dx.doi.org/10.1108/01443579810206334 
Mathew, S. (2007). An inspection maintenance strategy using the inspection factor. International Journal of Quality \& Reliability Management, 25(5), 532-540. http://dx.doi.org/10.1108/02656710810873916

Mishra, P. R., Anand, D., \& Kodali, R. (2006). Development of a framework for world-class maintenance systems. Journal of Advanced Manufacturing Systems, 5(2), 141-165. http://dx.doi.org/10.1142/S0219686706000807

Nakajima, S. (1988). Introduction to Total Productive Maintenance (TPM), Cambridge: Productivity Press.

Nguyen, D. Q., \& Bagajewicz, M. (2008). Optimization of Preventive Maintenance Scheduling in Processing Plants. Proceedings of the $18^{\text {th }}$ European Symposium on Computer Aided Process Engineering, Lyon. http://dx.doi.org/10.1016/S1570-7946(08)80058-2

Parida, A. (2007). Study and analysis of maintenance performance indicators (MPIs) for LKAB. Journal of Quality in Maintenance Engineering, 13(4), 325-337. http://dx.doi.org/10.1108/13552510710829434

Parida, A., \& Kumar, U. (2006). Maintenance performance measurement (MPM): issues and challenges. Journal of Quality in Maintenance Engineering, 12(3), 239-249. http://dx.doi.org/10.1108/13552510610685084

Pinjala, S. K., Pintelon, L., \& Vereecke, A. (2006). An empirical investigation on the relationship between business and maintenance strategies. International Journal of Production Economics, 104(1), 214-229. http://dx.doi.org/10.1016/j.ijpe.2004.12.024

Reis, A. C. B., Costa, A. P. C. S., \& Almeida, A. T. D. (2009). Journal of Quality in Maintenance Engineering, 15(3), 259-270. http://dx.doi.org/10.1108/13552510910983206

Reyes, J. A. E., Eldridge, S., Barber, K. D., \& Meier, H. S. (2010). Overall equipment effectiveness (OEE) and process capability (PC) measures: A relationship analysis. International Journal of Quality \& Reliability Management, 27(1), 48-62. http://dx.doi.org/10.1108/02656711011009308

Sachdeva, A., Kumar, D., \& Kumar, P. (2008). Planning and optimizing the maintenance of paper production systems in a paper plant. Computers \& Industrial Engineering, 55(4), 817-829. http://dx.doi.org/10.1016/j.cie.2008.03.004

Shahin, A. (2005). Total Productive Administration (TPA): Simulating TPM Methodology for Product Support and Administration. Proceedings of the $3^{\text {rd }}$ International Management Conference, Sharif University of Technology, 20-22 December, Tehran.

Shahin, A., \& Ahmadi, H. (2008). Principles and Techniques of Lean Six Sigma. Isfahan: Arkan Publication.

Tahir, Z., Prabuwono, A. S., \& Aboobaider, B. M. (2008). Maintenance Decision Support System in Small and MediumIndustries: An Approach to New Optimization Model. International Journal of Computer Science \& Network Security, 8(11), 155-162.

Veldman, J., Klingenberg, W., \& Wortmann, H. (2011). Managing condition-based maintenance technology: A multiple case study in the process industry. Journal of Quality in Maintenance Engineering, 17(1), 40-62. http://dx.doi.org/10.1108/13552511111116240

Wang, T. Y., \& Pan, H. C. (2011). Improving the OEE and UPH data quality by Automated Data Collection for the semiconductor assembly industry. Expert Systems with Applications, 38(5), 5764-5773. http://dx.doi.org/10.1016/j.eswa.2010.10.056

Weinstein, L., \& Chung, C. H. (1999). Integrating maintenance and production decisions in a hierarchical production planning environment. Computers \& Operations Research, 26(10/11), 1059-1074. http://dx.doi.org/10.1016/S0305-0548(99)00022-2

Wen, J. S., Feng, X., Chang, D., \& Shun, P. (2009). Tool maintenance optimization for multi-station machining systems with economic consideration of quality loss and obsolescence. Robotics \& Computer-Integrated Manufacturing, 26, 145-155. http://dx.doi.org/10.1016/j.rcim.2009.07.005

Zuashkiani, A., Rahmandad, H., \& Jardine, A. (2011). Mapping the dynamics of overall equipment effectiveness to enhance asset management practices. Journal of Quality in Maintenance Engineering, 17(1), 74-92. http://dx.doi.org/10.1108/13552511111116268 
Table 1. Data obtained from equipments

\begin{tabular}{|c|c|c|c|c|c|c|}
\hline Eq. No. & MTBF(Hr) & MTTR(Hr) & Availability(\%) & Performance(\%) & Quality(\%) & OEE $(\%)$ \\
\hline 1 & 185.9 & 3.18 & 98.32 & 92.1 & 100 & 91 \\
\hline 2 & 185.2 & 3.86 & 97.96 & 94.2 & 96.88 & 89 \\
\hline 3 & 181.5 & 7.5 & 96.03 & 96.3 & 83.54 & 77 \\
\hline 4 & 174.3 & 14.7 & 92.22 & 82 & 83.53 & 63 \\
\hline 5 & 176.6 & 12.44 & 93.24 & 87 & 92.8 & 75 \\
\hline 6 & 179.7 & 9.34 & 95.06 & 88 & 91 & 76 \\
\hline 7 & 13 & 26 & 33 & 73 & 83.54 & 20 \\
\hline 8 & 164.9 & 24.18 & 87.21 & 81 & 83 & 59 \\
\hline 9 & 168.8 & 20.23 & 88.3 & 83 & 85 & 62 \\
\hline 10 & 13 & 28 & 32 & 76 & 97 & 32 \\
\hline 11 & 174.6 & 43.66 & 80 & 84 & 77 & 52 \\
\hline 12 & 136 & 32 & 81 & 59 & 90 & 43 \\
\hline 13 & 48 & 24 & 67 & 64 & 90 & 38 \\
\hline 14 & 13.36 & 10.64 & 55.67 & 59.88 & 92 & 30.66 \\
\hline 15 & 128.6 & 34 & 87 & 94 & 91 & 74 \\
\hline 16 & 12.33 & 21 & 37 & 54 & 80 & 16 \\
\hline 17 & 191.7 & 16.67 & 92 & 89 & 62.3 & 51 \\
\hline 18 & 19.1 & 15 & 56 & 85 & 73.5 & 35 \\
\hline 19 & 26.59 & 17 & 61 & 89 & 64.5 & 35 \\
\hline 20 & 132.2 & 36 & 78.6 & 64.3 & 92.8 & 47 \\
\hline 21 & 157 & 12 & 92.9 & 52.4 & 97.3 & 47.4 \\
\hline 22 & 153.5 & 15 & 91.1 & 66.8 & 97.3 & 59.2 \\
\hline 23 & 187 & 22 & 89.5 & 81 & 95 & 69 \\
\hline 24 & 29 & 62 & 32 & 52 & 86 & 14 \\
\hline 25 & 180 & 23 & 89 & 55 & 91 & 45 \\
\hline 26 & 35 & 32 & 52 & 49 & 92 & 23 \\
\hline 27 & 30 & 78 & 52 & 63 & 92 & 30 \\
\hline 28 & 18 & 51 & 26 & 55 & 90 & 13 \\
\hline 29 & 16 & 54 & 23 & 50 & 88 & 10 \\
\hline 30 & 120 & 75 & 62 & 73 & 92 & 42 \\
\hline
\end{tabular}

Table 2. Linear regression analysis between OEE and MTBF

\begin{tabular}{|c|c|c|c|c|c|}
\hline \multirow[t]{2}{*}{ Model } & \multicolumn{2}{|c|}{ Unstandardized coefficients } & \multirow{2}{*}{$\begin{array}{c}\begin{array}{c}\text { Standardized } \\
\text { coefficient }\end{array} \\
\text { Beta } \\
\end{array}$} & \multirow[t]{2}{*}{$\mathrm{t}$} & \multirow{2}{*}{ Sig. } \\
\hline & $\mathrm{B}$ & Std. error & & & \\
\hline Constant & 18.185 & 3.963 & & 4.589 & 0.000 \\
\hline MTBF & 0.268 & 0.030 & 0.858 & 8.821 & 0.000 \\
\hline
\end{tabular}

Dependent variable: OEE 


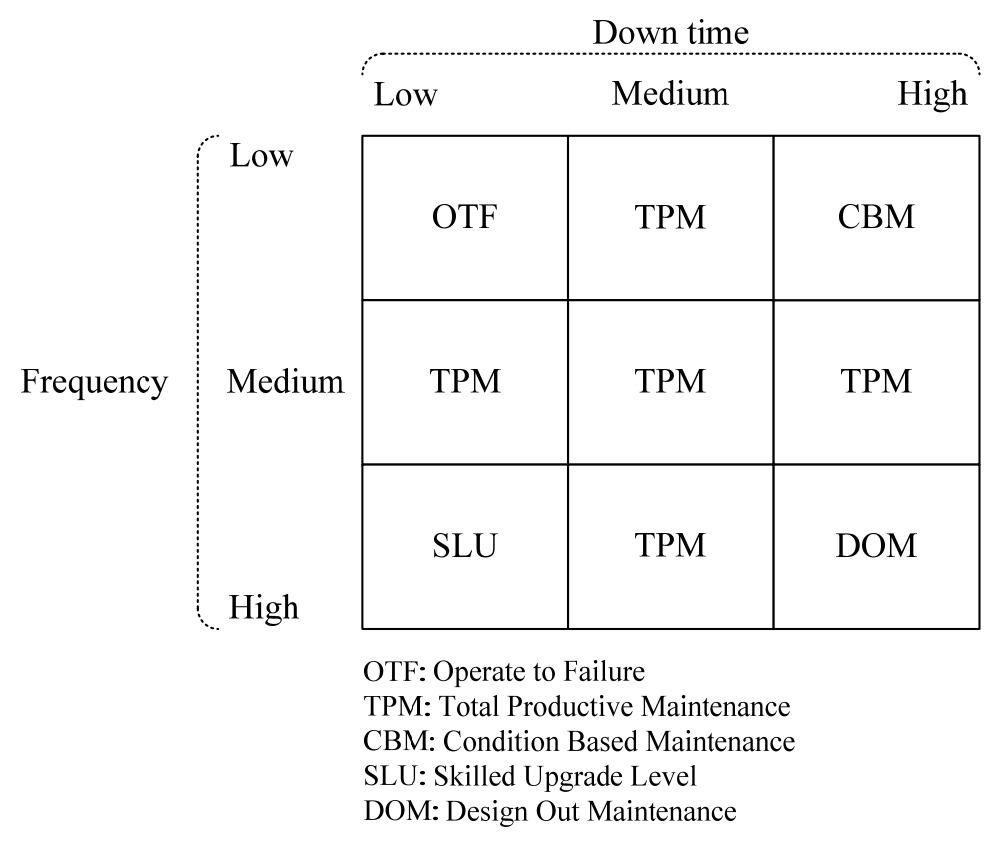

Figure 1. Decision Making Grid (Labib, 1998)

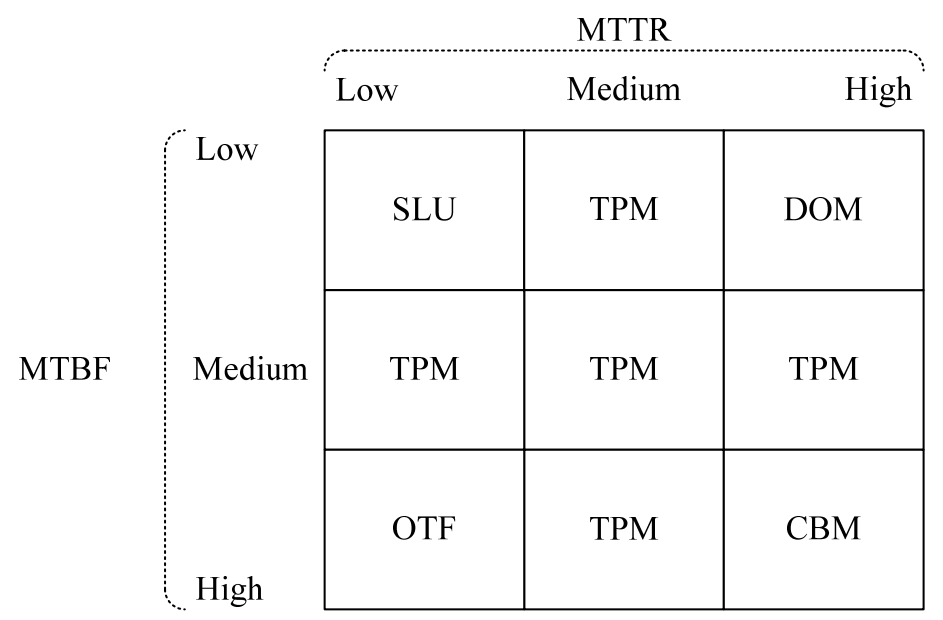

Figure 2. Modified Decision Making Grid

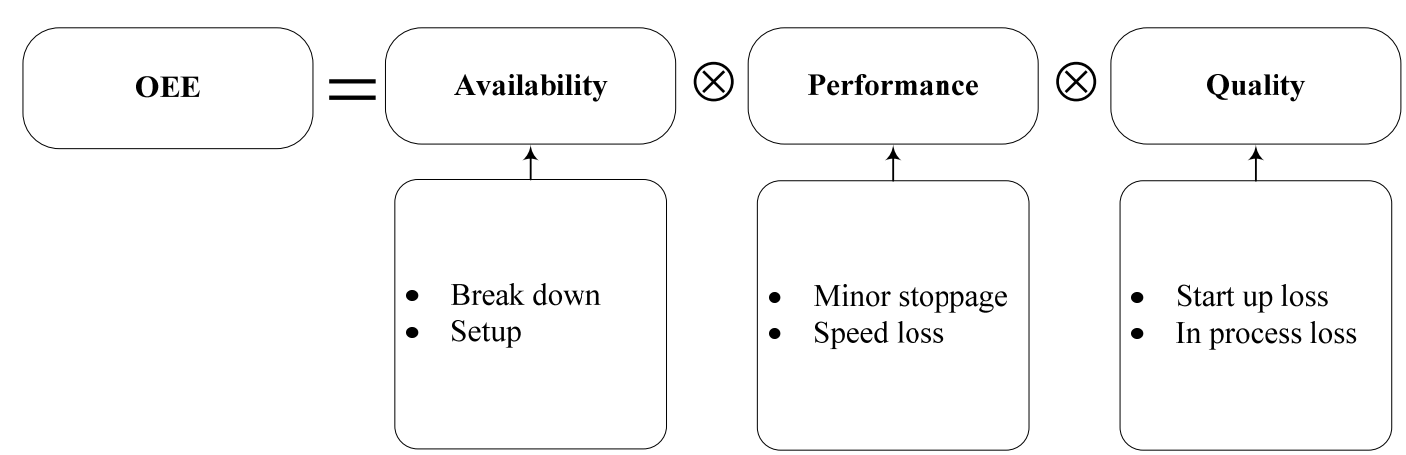

Figure 3. Overall Equipment Effectiveness (Shahin and Ahmadi, 2008) 


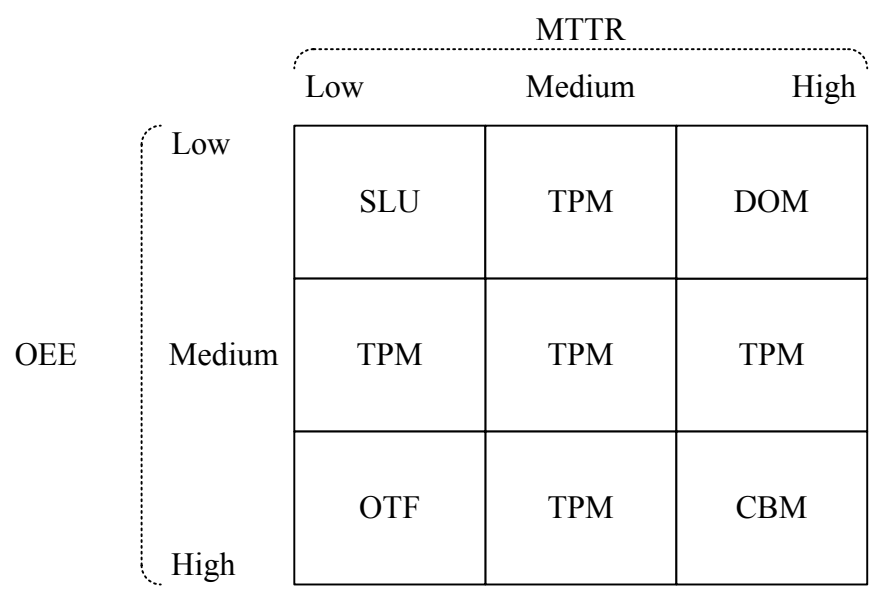

Figure 4. Developed Decision Making Grid

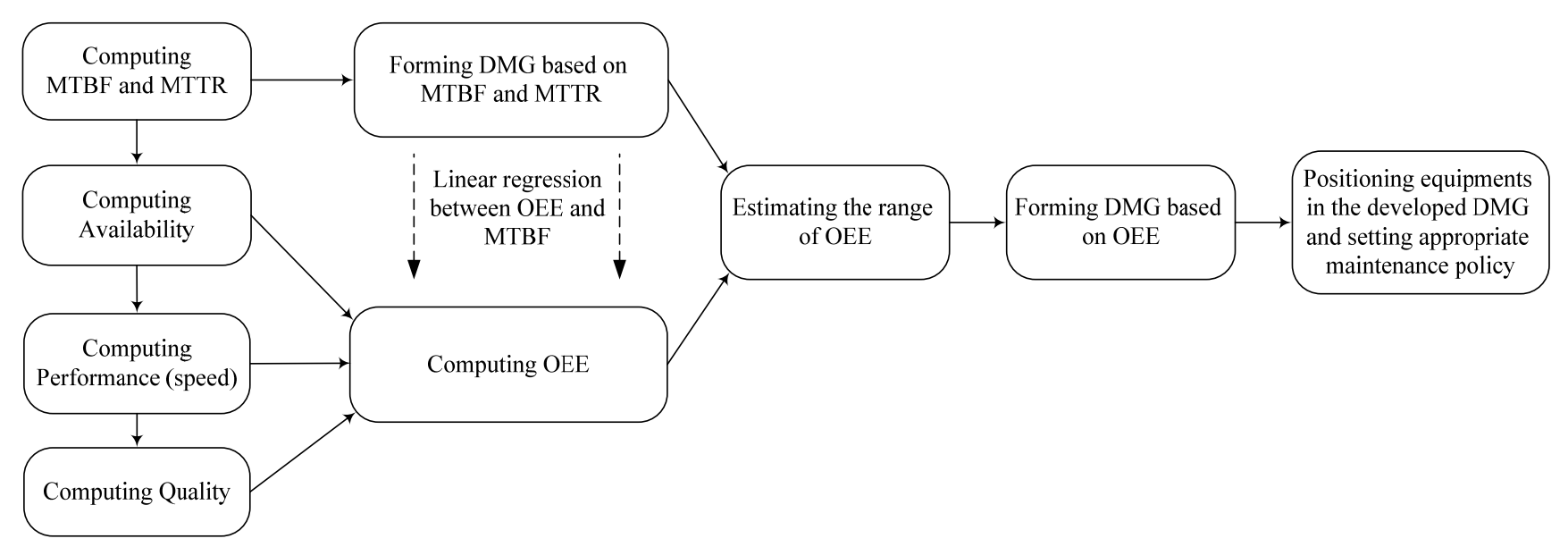

Figure 5. The research approach

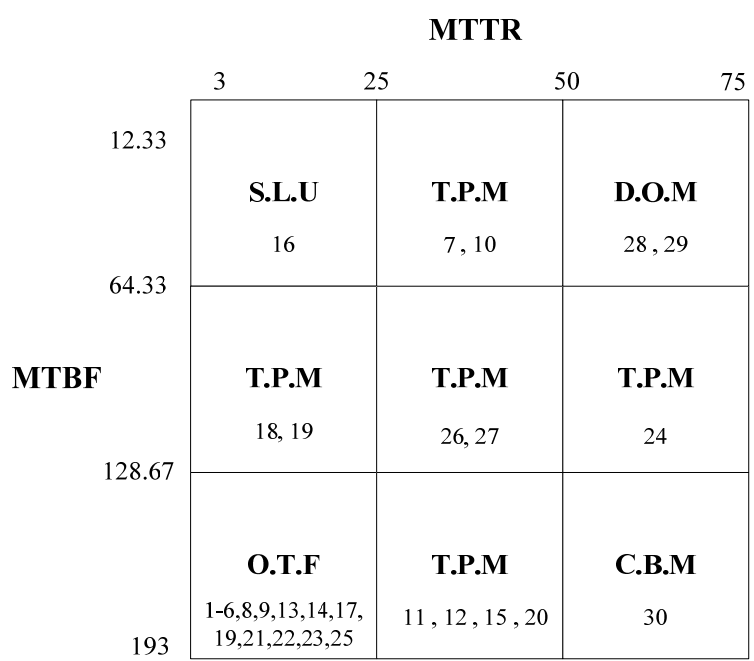

Figure 6. Positioning the equipments in DMG based on MTBF and MTTR values 


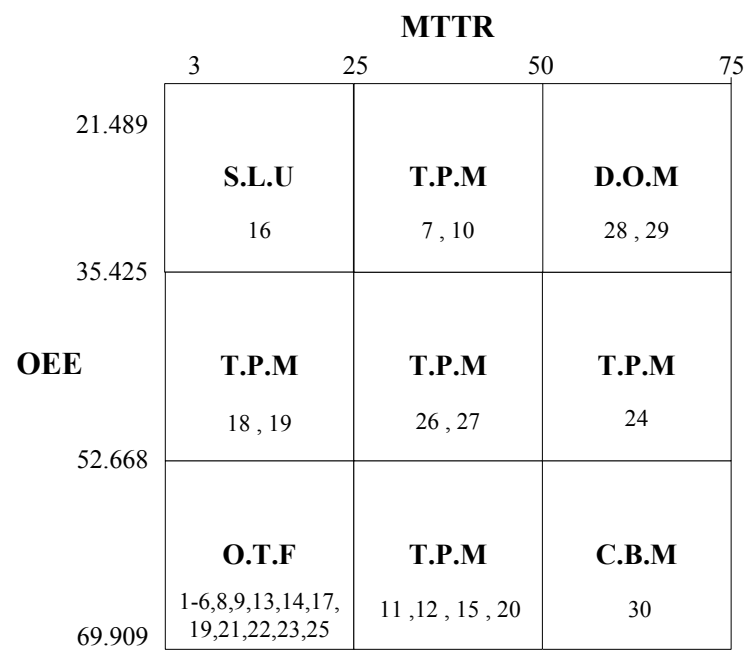

Figure 7. Positioning the equipments in DMG based on OEE and MTTR values 